\title{
A CASE OF VALPROATE INDUCED HEPATITIS IN AN ELDERLY SUBJECT - A RARE CASE REPORT
}

Patil B. V1, Ashok Binjawadgi², Basavambika Anandi³ ${ }^{3}$ J. Pradeep ${ }^{4}$

\section{HOW TO CITE THIS ARTICLE:}

Patil B V, Ashok Binjawadgi, Basavambika Anandi, J Pradeep. "A case of valproate induced hepatitis in an elderly subject - a rare case report". Journal of Evolution of Medical and Dental Sciences 2013; Vol2, Issue 29, July 22; Page: 5492-5494.

ABSTRACT: Sodium Valproate is a branched chain aliphatic carboxylic acid with broadspectrum anti-seizure activity effective in the treatment of absence, myoclonic, partial, and tonic-clonic seizures. The most common side effects are transient gastrointestinal symptoms, including anorexia, nausea, and vomiting.

Liver injury may follow the inhalation, ingestion, or parenteral administration of a number of pharmacologic and chemical agents.

The risk is greatest for children under two years of age and for those taking multiple medications. A rare complication in adults is a fulminant hepatitis that is frequently fatal. We would like to report a case of Sodium Valproate induced hepatitis in an elderly male who presented with dark urine, fever, generalized weakness and other symptoms suggestive of drug induced hepatitis.

KEY WORDS: Sodium Valproate, Drug induced hepatitis, adverse drug reactions.

INTRODUCTION: Sodium Valproate is a branched chain aliphatic carboxylic acid with broadspectrum anti-seizure activity effective in the treatment of absence, myoclonic, partial, and tonic-clonic seizures. ${ }^{1}$ Valproic acid has several effects on hepatic function. Elevation of hepatic transaminases in plasma is observed in up to $40 \%$ of patients and often occurs asymptomatically during the first several months of therapy. A rare complication in adults is a fulminant hepatitis that is frequently fatal. ${ }^{2}$ Liver injury may follow the inhalation, ingestion, or parenteral administration of a number of pharmacologic and chemical agents. ${ }^{3}$ We present here a case of Sodium Valproate induced hepatitis, which was neglected and later showed remarkable improvement on withdrawing the drug.

CASE REPORT: A 76 year old male patient with complaints of fever, loss of appetite and nausea for 15 days along with generalized weakness, yellow discoloration of sclera for a week was admitted at a tertiary care centre in Gulbarga. The patient was a hypertensive on Telmisartan $\mathrm{H}$ once daily with history of cerebrovascular accident and two episodes of generalized tonic clonic seizures on treatment with Clopidogrel75mg once daily, Valproate Chrono 500mg twice daily.

On examination patient was normotensive, icterus was present, and abdomen was tender with no apparent organomegaly. Laboratory findings at presentation were as follows: Total bilirubin 5.58mg/dl (normal: $0.2-1.2 \mathrm{mg} / \mathrm{dl}$ ), direct bilirubin $3.01 \mathrm{mg} / \mathrm{dl}$ (normal: 0.1 $0.6 \mathrm{mg} / \mathrm{dl}$ ), indirect bilirubin $2.57 \mathrm{mg} / \mathrm{dl}$ (normal: $0.1-0.4 \mathrm{mg} / \mathrm{dl}$ ), Alaninetransaminase 200.8 IU/L (normal: 5-35 IU/L), Aspartate transaminase $174.6 \mathrm{U} / \mathrm{ml}$ (normal: ), Alkaline phosphatase276.9 IU/L (normal: 60-170IU/L), total proteins 6.90g/dl (normal: 6.5-8.3g/dl). A complete ultrasound of the abdomen was normal. No other abnormal lab findings were found (Table-1)

The case was diagnosed and treated as viral hepatitis with old cerebrovascular accident. Valproate was continued as once daily dose. Patient did not show significant improvement and 
was discharged and taken to previously treating neurophysician. Wherein on detailed history taking it was revealed that while patient was on Valproate for last two years, he had been having dark coloured urine since one year. This history was neglected in the tertiary hospital where he was treated for viral hepatitis. On review, hepatitis was suspected to be drug induced and Valproate was withdrawn. Patient showed remarkable improvement in four days.

Table - 1: Hepatitis in a patient treated with Sodium Valproate.

\begin{tabular}{|c|c|c|c|c|}
\hline Test & $\begin{array}{c}\text { During Sodium } \\
\text { Valproate Therapy }\end{array}$ & At presentation & $\begin{array}{c}\text { After drug } \\
\text { withdrawal }\end{array}$ & $\begin{array}{c}\text { Reference } \\
\text { range }\end{array}$ \\
\hline Total bilirubin (mg/dL) & 8.34 & 5.58 & 0.8 & $0.2-1.2$ \\
\hline Direct bilirubin (mg/dL) & 7.17 & 3.01 & 0.5 & $0.1-0.6$ \\
\hline Indirect bilirubin (mg/dl) & 1.17 & 2.57 & 0.3 & $0.1-0.4$ \\
\hline ALT (IU/L) & 584 & 200.8 & 18 & $5-35$ \\
\hline AST (IU/L) & - & 174.6 & 14 & $7-38$ \\
\hline ALP (IU/L) & 460 & 276.9 & 156 & $60-170$ \\
\hline Total proteins (g/dL) & 6.80 & 6.90 & - & $6.5-8.3$ \\
\hline
\end{tabular}

ALT: Alanine Transaminase, AST: Aspartate Transaminase, ALP: Alkaline Phosphatase

DISCUSSION: Valproate is an effective and popular anti-seizure drug and only a very small number of patients have had severe toxic effects from its use. The most common side effects are transient gastro intestinal symptoms, including anorexia, nausea, and vomiting in $\sim 16 \%$ of patients. ${ }^{2}$ The idiosyncratic toxicity of valproate is largely limited to hepatotoxicity but this may be severe. The risk is greatest for patients under two years of age and for those taking multiple medications. Initial aspartate transaminase values may not be elevated in susceptible patients although these levels eventually become abnormal. ${ }^{4}$

Current mechanistic concepts of drug induced liver injury can be summarized in a 3step model that limits its principle mechanisms to three main ways of initial injury, i.e. direct cell stress, direct mitochondrial impairment, and specific immune reactions. Subsequently, initial injury initiates further downstream events, leading to mitochondrial permeability transition, which then results in apoptotic or necrotic cell death. ${ }^{5}$

In upto $44 \%$ of patients chronic dosing with Sodium Valproate may be associated with elevation in the transaminases during the first months of therapy. Although the overall incidence is estimated at 1 in 5000 to 1 in 50000, the occurrence of fatal hepatotoxicity could be as high as 1 in 800 to 1 in 500 in the high-risk groups. ${ }^{6}$

It is distinctive in our case that the patient has been having hepatotoxicity since a year after starting valproate as evidenced by dark urine with no other adverse effects until then. He currently presented with fever and abdominal tenderness with generalized weakness. And the symptoms subsided as soon as causative drug was withdrawn as evidenced by the laboratory values (Table - 1) and retraction of symptoms.

Currently the patient has been put on Phenobarbitone $60 \mathrm{mg} /$ day as replacement for Sodium Valproate.

It is essential that any patient, presenting with jaundice or altered biochemical liver tests be questioned carefully about exposure to chemicals used in work or at home, drugs taken by prescription or bought over the counter, and herbal or alternative medicines ${ }^{3}$. 
Treatment of toxic and drug induced hepatitis is largely supportive. Withdrawal of the suspected agent is indicated at the first sign of an adverse reaction ${ }^{3}$.

CONCLUSION: In conclusion physicians prescribing Sodium Valproate should go for careful liver function monitoring. Hepatitis is not uncommon in elderly subjects on Sodium Valproate, hence detailed past drug history is important in cases of hepatitis.

\section{REFERENCES:}

1. Tripathi KD. Antiepileptic drugs. Essentials of Medical Pharmacology $6^{\text {th }}$ edition, Jaypee Publishers; 2010.Chapter 30.P. 401.

2. Brunton LL, Chabner BA, Knollmann BC. Pharmacotherapy of epilepsies. Goodman and Gilman's The Pharmacological Basis of Therapeutics $12^{\text {th }}$ edition, McGraw Hill Publications; 2011. Section II Neuropharmacology; Chapter 21.P. 583 - 587

3. Dan L.Longo, Anthony S. Fauci, Dennis L. Kasper et. al. Toxic and drug induced hepatitis, Harrison's Principles of Internal Medicine18th Edition; McGraw Hill Publications. Chapter 305 - Online edition

4. Bertram G. Katzung. Anti-seizure drugs, Basic and Clinical Pharmacology $11^{\text {th }}$ edition; 2009, Section V Drugs that act in the central nervous system; McGraw Hill Publications. Chapter 24. P. 399 - 414

5. Stefan Russmann, Gerd A. Kullak-Ublick and IgnazioGrattagliano.Current Concepts of Mechanisms in Drug-Induced Hepatotoxicity. Current Medicinal Chemistry, 2009, 16, 3041-3053

6. Philippe ER Lheureux, Andrea Penaloza, SoheilZahir, Mireille Gris. Science Review: Carnitine in the treatment of valproic acid - induced toxicity - what is the evidence? Critical Care. Vol. 9(5), 2005.

\section{AUTHORS: \\ 1. Patil B. V. \\ 2. Ashok Binjawadgi \\ 3. Basavambika Anandi \\ 4. J. Pradeep}

\section{PARTICULARS OF CONTRIBUTORS:}

1. Professor, Department of Pharmacology, MRMC, Gulbarga.

2. Associate Professor, Department of Pharmacology, MRMC, Gulbarga.

3. PG Resident, Department of Pharmacology, MRMC, Gulbarga.
4. PG Resident, Department of Pharmacology, MRMC, Gulbarga.

\section{NAME ADRRESS EMAIL ID OF THE CORRESPONDING AUTHOR:}

Dr. Patil B. V,

Professor, Dept. of Pharmacology,

MR Medical College, Sedam Road,

Gulbarga - 585102.

Email-drpatilbv@gmail.com

Date of Submission: 10/07/2013.

Date of Peer Review: 11/07/2013.

Date of Acceptance: 19/07/2013.

Date of Publishing: 22/07/2013 